\title{
AUTOMATING STRUCTURAL ANALYSIS OF SPACECRAFT VEHICLES
}

\author{
GLENN A. HRINDA \\ NASA LANGLEY RESEARCH CENTER, HAMPTON VA, USA
}

\begin{abstract}
A major effort within NASA's vehicle analysis discipline has been to automate structural analysis and sizing optimization during conceptual design studies of advanced spacecraft. Traditional spacecraft structural sizing has involved detailed finite element analysis (FEA) requiring large degree-of-freedom (DOF) finite element models (FEM). Creation and analysis of these models can be time consuming and limit model size during conceptual designs. The goal is to find an optimal design that meets the mission requirements but produces the lightest structure. A structural sizing tool called HyperSizer ${ }^{\mathrm{TM}}$ has been successfully used in the conceptual design phase of a reusable launch vehicle and planetary exploration spacecraft. The program couples with FEA to enable system level performance assessments and weight predictions including design optimization of material selections and sizing of spacecraft members. The software's analysis capabilities are based on established aerospace structural methods for strength, stability and stiffness that produce adequately sized members and reliable structural weight estimates.
\end{abstract}

The software also helps to identify potential structural deficiencies early in the conceptual design so changes can be made without wasted time. HyperSizer ${ }^{\mathrm{TM}}$, s automated analysis and sizing optimization increases productivity and brings standardization to a systems study. These benefits will be illustrated in examining two different types of conceptual spacecraft designed using the software. A hypersonic air breathing, single stage to orbit (SSTO), reusable launch vehicle (RLV) will be highlighted as well as an aeroshell for a planetary exploration vehicle used for aerocapture at Mars. By showing the two different types of vehicles, the software's flexibility will be demonstrated with an emphasis on reducing aeroshell structural weight. Member sizes, concepts and material selections will be discussed as well as analysis methods used in optimizing the structure. Analysis based on the HyperSizer $^{\mathrm{TM}}$ structural sizing software will be discussed. Design trades required to optimize structural weight will be presented.

\begin{tabular}{ll} 
Al & Nomenclature \\
\cline { 2 - 2 } BMI & Aluminum \\
c.g. & $\begin{array}{l}\text { Bismaleimide } \\
\text { Center-of-gravity }\end{array}$ \\
FEA & Degree-of-freedom \\
FEM & Finite Element Analysis \\
FWD & Finite Element Model \\
ISAT & Forward \\
& Intercenter System Analysis \\
ISS & Team \\
JSC & International Space Station \\
LH2 & Johnson Space Center \\
LOX & Liquid Hydrogen \\
PM & Liquid Oxygen \\
RLV & Propulsion Module \\
SSTO & Reusable Launch Vehicle \\
Ti & Single Stage to Orbit \\
TPS & Titanium \\
& Thermal Protection System
\end{tabular}

\section{Introduction}

Vehicle analysis at the systems level has various methods and tools that have been developed to help increase a conceptual vehicles design cycle. Within structural analysis, weight estimation of the aeroshell and airframe at minimal cost to mission performance is a main issue. A structural sizing tool developed by Collier Research called HyperSizer ${ }^{\mathrm{TM}}$ has been used on a variety of vehicle structures to help automate the structural sizing process. The software tool was used to size an air breathing RLV shown in Figure 1 and an aerocapture aeroshell for a mission to Mars as shown in Figure 2.

The software enables many candidate structural systems to be analyzed and optimized at a fraction of the time a traditional FEA takes. Complex aerospace structural concepts such as J and Z stiffened panels, composite laminates and isogrids could be evaluated without the need of resizing finite element meshes. Many different composite materials could also be investigated such as laminates, foam cores and honeycombs. Highly 


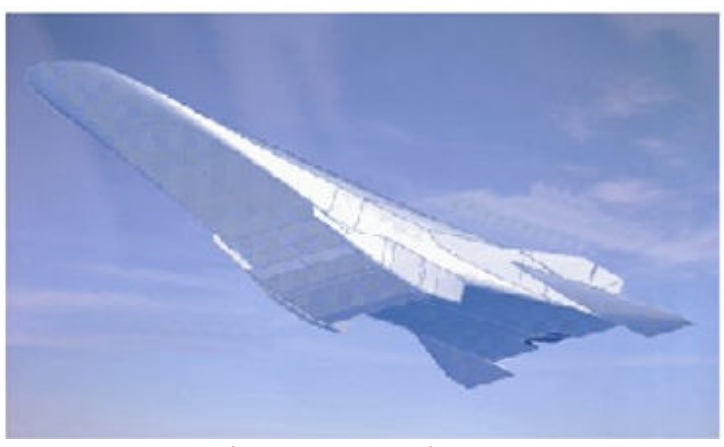

Figure 1. RLV/SSTO

detailed FEM's with many DOF are not required to size panel structures. Time spent in modeling and analysis will be reduced and still produce the lightest structural concept. HyperSizer ${ }^{\mathrm{TM}}$ documents all structural weight results so that they can be incorporated into systems studies for enhancing credibility of the final design. ${ }^{7}$

The structure for a futuristic air breathing, hypersonic RLV was analyzed using HyperSizer ${ }^{\mathrm{TM}}$ to obtain an efficient airframe meeting SSTO access-to-space requirements. The vehicle's major goals are to provide low-cost space access 100 times cheaper than present day shuttle costs as well as increasing flight safety. Achieving these goals will require advancing space launch technologies such as increased engine thrust/weight ratio, increasing vehicle life and maintainability, reducing structural weight and lowering production costs through reduced design complexity and tooling. Integration of system analysis capabilities and technology evaluation assessments, which includes design tools and methods, must be accomplished to advance the state-of-the-art in vehicle design and analysis. ${ }^{3}$

One of the tools evaluated was HyperSizer ${ }^{\mathrm{TM}}$ that was being used by ISAT to evaluate $3^{\text {rd }}$ Generation structural concepts and demonstrate the program's fast sizing ability and design methodology. Structural weight reduction was performed on the airframe without using a finite element based optimization procedure. Detailed structural concepts such as blade stiffened, corrugated and isogrid panels were used to design the scramjet lifting body SSTO for carrying a 25,000-pound payload to the International Space Station (ISS) orbit.

HyperSizer ${ }^{\mathrm{TM}}$ was also used in a system study of a planetary exploration spacecraft to Mars using a technique called aerocapture to help minimize vehicle weight. Aerocapture slows the spacecraft for orbit insertion in one pass through an atmosphere by using the aerodynamics of its aeroshell. The technology has shown an increase in mission performance by decreasing propellant weight that is normally used for deceleration. Associated benefits also include lower mission costs by using a less expensive launch vehicle, shorter cruise time to the destination, and minimal chemical propulsion system mass for orbit capture. The mission was an orbiter/lander combination that separates prior to aerocapture at Mars. The orbiter was designed for aerocapture and used HyperSizer ${ }^{\mathrm{TM}}$ to investigate the optimal structural concept, material and size of the aeroshell. Design trades were performed to find the minimal structural weight required to support a Delta IV heavy launch and entry loads during aerocapture. Dynamic modes were also investigated. The original structural analysis relied on a highly refined mesh and large DOF FEM to size the structure for weight estimation. The structure was reanalyzed with HyperSizer ${ }^{\mathrm{TM}}$ by using a single coarsely meshed FEM to perform all structural sizing without the need to remesh for different structural concepts. The aeoeshell design used composites for the orbiter structure and a truss system to support the lander inside the aeroshell. The lander was not sized and was only used to help establish the mission parameters for getting a science payload to the Mars surface.

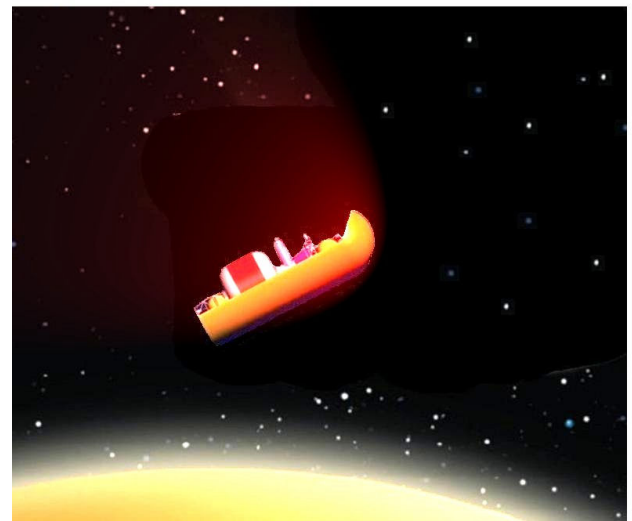

Figure 2. Slender Rigid Body during Aerocapture

\section{Conceptual SSTO Design}

The conceptual lifting body SSTO vehicle was used by ISAT as a baseline to test design and analysis methods used among the various NASA centers involved with aerospace vehicle designs. The overall dimensions of the vehicle are shown in Figure 3. This study focused on the weight reduction and strength requirements of the major load carrying structural members. The SSTO lifting body, with its non-circular cross section, must be lightweight, fully reusable and easily maintained. A major challenge was to efficiently design the tank system necessary for an SSTO to gain ISS orbit. Current tank system designs that were considered were the dual-lobed, such as in the X-33/RLV, and quadlobed tanks. ${ }^{1}$ Each tank concept offered higher 


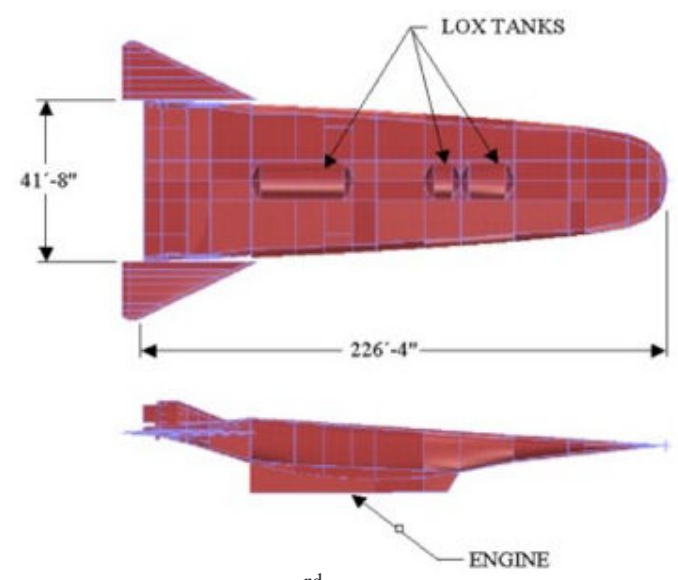

Figure 3. $3^{\text {rd }}$ Generation SSTO

packaging efficiency than circular tanks, but both still had large gaps between the vehicle outer mold line and the external surfaces of the tank structure. Also considered were conformal tanks that follow the outer mold line of the non-circular vehicle. They offer the most efficient use of internal volume but require higher structure mass.

All propellants are LOX and LH2 with an approximate weight ratio of $3: 1$, respectively. Estimated weights for the engine, control surfaces, landing gear and subsystems were used. Loading conditions were from a $1.5 \mathrm{~g}$ vertical pull-up maneuver with a fully loaded aerodynamically trimmed vehicle. The trimmed vehicle had the c.g. approximately at 55\% from the leading nose edge.

The tank configuration chosen for the $3^{\text {rd }}$ generation concept vehicle used conformal LH2 tanks and single lobed non-conformal cylindrical LOX tanks. ${ }^{1}$

Conformal tanks were originally chosen for the LOX but preliminary panel sizing of the outer skin panels of the vehicle revealed large weight gains were necessary to keep mid-span deflections minimal. The preliminary panel sizing is discussed later in this paper. The much lower density of the LH2 $\left(4.75 \mathrm{ft}^{3}\right)$ and lower operating pressure produced panel sizes that could support a conformal tank arrangement as shown in Figure 4. The LOX tanks were pressurized to 20 psi and the LH2 tanks held at 5 psi.

The LOX was arranged into three tanks supported between the two keel beams as shown in Figure 4. This arrangement allowed for the LOX tanks to be located near the vehicle takeoff c.g. and also allowed the LOX weight to help in trimming the vehicle when aero loads were applied. The tank positions were adjusted to keep the vehicle c.g. location near the $55 \%$ position. Bulkhead locations divided the fuselage into sections convenient for supporting tanks and defining the payload compartment. Structural supports for the main landing gear and nose gear were also included.

The cryogenic fuels, $\mathrm{LH} 2$ at $-423^{\circ} \mathrm{F}$ and LOX at $297^{\circ} \mathrm{F}$, will create thermal gradients throughout the airframe and induce stress. Their contribution to sizing the airframe members was not considered in this study. The possible loads produced from these temperature extremes could introduce load cases not allowed in this design. This would be a subject of greater interest in further detail analysis.

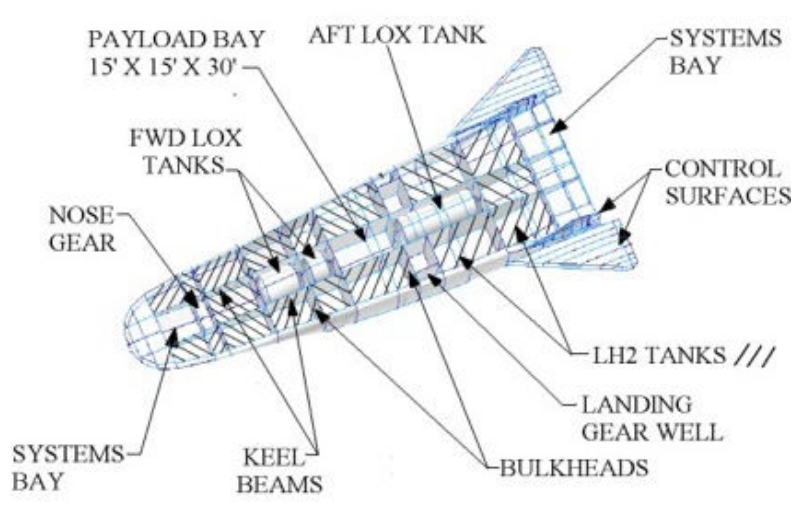

Figure 4. Vehicle Layout

\section{Structural Analysis Methods}

The structural sizing of the SSTO $3^{\text {rd }}$ generation concept vehicle was performed with a typical FEA approach combined with a non-FEA sizing program called HyperSizer $^{\mathrm{TM}}$. A FEM of the vehicle was created using basic shell and beam elements. A symmetric model was used with a coarse mesh as shown below in Figure $5 .^{2}$

The purpose of the model was not to perform the structural sizing and optimization usually performed in aircraft weight reduction analysis but to import the model with all loads into HyperSizer ${ }^{\mathrm{TM}}$. All sizing of the structure, which included margin checks, is performed inside HyperSizer ${ }^{\mathrm{TM}}$. Optimization was achieved through HyperSizer ${ }^{\mathrm{TM}}$ 's approach to quickly identify the best panel or beam section as well as material selection. ${ }^{7}$

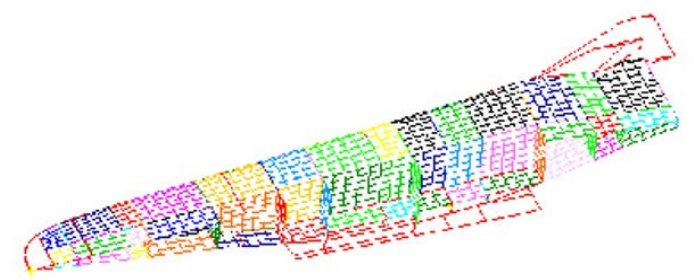

Figure 5.

$3^{\text {rd }}$ Generation Concept Vehicle Asymmetry FEM 


\section{Why use HyperSizer?}

Aerospace structures contain complex geometry and load distributions that are highly indeterminate and historically demanded FEA to solve. Performing structural analysis and sizing optimization has required large DOF models with long solution run times. A software product called HyperSizer ${ }^{\mathrm{TM}}$ can help simplify structural sizing and reduce design analysis time. HyperSizer ${ }^{\mathrm{TM}}$ helps to automate the sizing of structures by reducing flight and acceleration loads into force and moment components on panels and beams throughout the vehicle. The sizing includes finding the optimal material combinations and panel and beam dimensions such as thickness, depths and spacing. The code is not a FEA or computer aided design package.

HyperSizer ${ }^{\mathrm{TM}}$ adds to the capabilities of these tools to allow the engineer to design, size and perform detailed failure analysis on a complete vehicle. ${ }^{7}$

\section{Optimization Capabilities}

Optimization capabilities within HyperSizer ${ }^{\mathrm{TM}}$ include finding minimum weight panel or beam concepts, material selections, cross sectional dimensions, thickness and lay-ups from a database of 50 different stiffened and sandwich designs as well as a database of composite, metallic, honeycomb and foam materials. ${ }^{5}$ The database is used to define structural families inside HyperSizer $^{\mathrm{TM}}$. The structural families include definitions for panels and beams such as the "uniaxial stiffened family", the "unstiffened plate/sandwich family" and the "open beam family". The panels may be stiffened with typical aerospace shapes or corrugated as shown in Figure 6. The grid-stiffened family of panels has recently been added to HyperSizer ${ }^{\mathrm{TM}}$. This allows for the sizing optimization of isogrids, orthogrids and general grid rib-stiffened panel concepts with either isotropic or composite materials. ${ }^{6}$
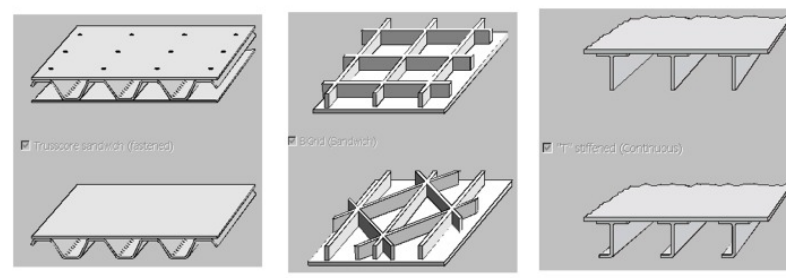

Figure 6. Corrugated, Blade Stiffened and Isogrid Panel Concepts

The panels may also be sandwich shapes containing foam or honeycomb materials as shown in Figure 7. HyperSizer $^{\mathrm{TM}}$ adds flexibility to the optimization process by allowing face sheet and core thickness as variables used as an optimization parameter. The beam family can be open or closed with both symmetric and unsymmetrical shapes. HyperSizer ${ }^{\mathrm{TM}}$ can limit an optimization to specific gages or specified material thickness if required during the design cycle. ${ }^{7}$ A stock list can be created to allow only members from the list to be applied to the current design variable.

\section{HyperSizer Coupling with NASTRAN}

The HyperSizer ${ }^{\mathrm{TM}}$ sizing software will solve problems with uniformly applied mechanical and thermal loads. These include in-plane shears, edge moments and inplane or through-the-thickness temperature gradients. The code uses panel and beam forces and moments computed from NASTRAN for sizing optimization and checking for failures in structures.

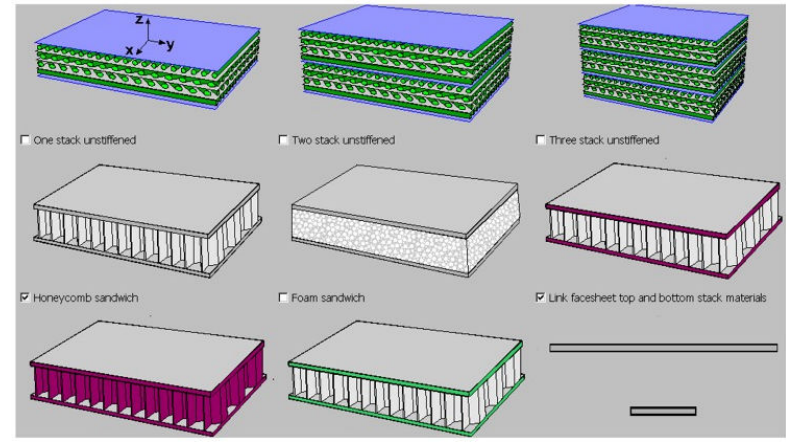

Figure 7. Foam and Honeycomb Panel Concepts

HyperSizer $^{\mathrm{TM}}$ uses equivalent panel formulations where complex 3-D panel shapes will be reduced to accurate 2-D planar elements. Equivalent 6 × 6 stiffness matrices are used in representing the group of finite elements making up the HyperSizer ${ }^{\mathrm{TM}}$ panel. The panels are represented in NASTRAN by the CQUAD4 and CTRIA3 planar elements. The PSHELL card is used to define the properties for these elements and the MAT2 card is used to define the material properties. HyperSizer ${ }^{\mathrm{TM}}$ will automatically generate the generalized stiffness for the panels and export the appropriate PSHELL and MAT2 cards into separate files. $^{4}$

Figure 8 shows the $3^{\text {rd }}$ generation concept vehicle FEA model and how panels with similar properties are grouped together into HyperSizer ${ }^{\mathrm{TM}}$ components. The HyperSizer ${ }^{\mathrm{TM}}$ model now has the necessary panel parameters to start sizing. To help narrow the selection of possible design choices, a preliminary panel sizing analysis was performed. ${ }^{2}$

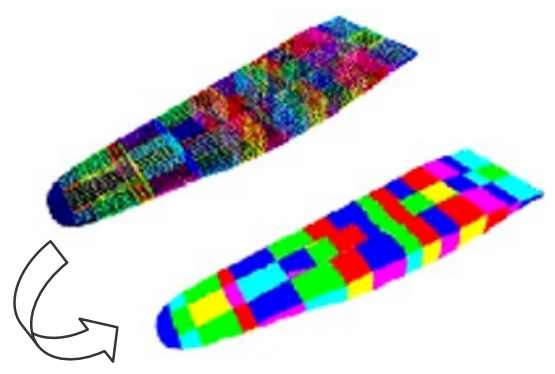

Figure 8. FEA to HyperSizer model 


\section{Preliminary Panel Sizing}

An initial panel sizing was performed to help select possible candidate panel designs before the HyperSizer $^{\mathrm{TM}}$ optimization process was started. The analysis was performed using HyperSizer ${ }^{\mathrm{TM}}$, s panel sizing analysis without FEA. Panel sizing of the vehicle skins was performed to determine if conformal tanks could be used for the LOX and LH2. Figure 9 shows the typical trial panel geometry and loading used for the LH2 tanks. Estimates for Nx and Ny in-plane loads were derived from hand equations with an applied 5 psi internal pressure load. The panel width was held at 60 " with span lengths varying at 30 ", 60 ", 90 " and $120 "$ ".

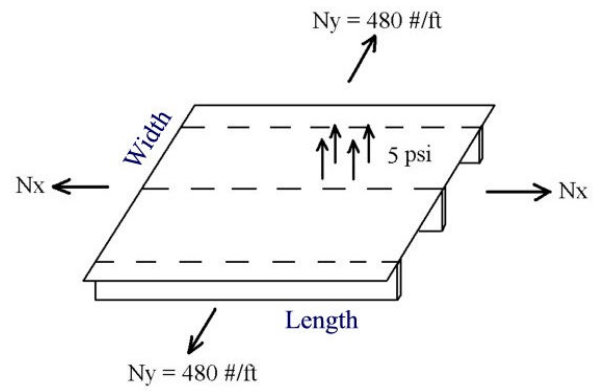

Figure 9. Bladed Panel used for Preliminary Sizing

Simply supported edge conditions were used to allow greater mid-span deflections. All mid-span deflections were held to $1 \%$ of the span length. The blade and skin thickness were given a range from 0.1 to 0.5 inches. Stiffener spacing was also allowed to vary from 4 through 20 inches. Strength and buckling margin checks were performed within HyperSizer ${ }^{\mathrm{TM}}$ and a 1.5 factor-of-safety applied. The trial panels tested were aluminum and graphite/epoxy. Figure 10 below shows the results for an aluminum bladed panel with $5 \mathrm{psi}$ LH2 tank pressure. As spans are increased there is an

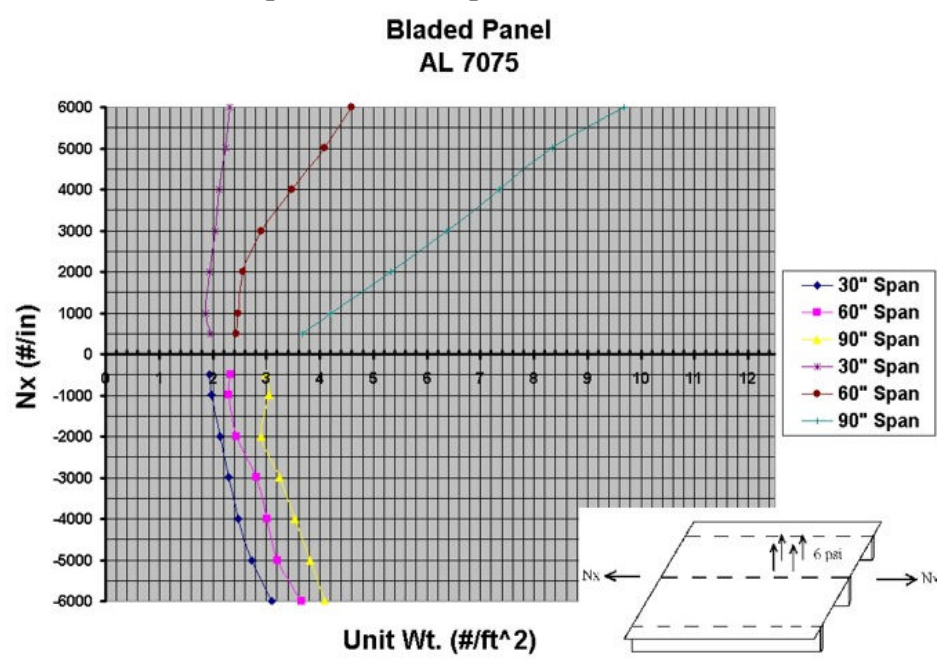

Figure 10. Bladed Panel Weight Curves expected rise in panel weight. Similar analysis for the 20 psi conformal LOX tanks showed excessive panel weights and growing sectional dimensions. The LOX conformal panels could not be efficiently designed for tank pressure plus the hydrostatic LOX head. The analysis, however, suggested that the LH2 blade stiffened conformal tanks could be further improved upon. The next phase of the design was to take the preliminary panel sizing results and apply them to a FEA/HyperSizer ${ }^{\mathrm{TM}}$ full model of the $3^{\text {rd }}$ generation concept vehicle.

\section{Vehicle Analysis}

The structural analysis on the $3^{\text {rd }}$ generation concept vehicle was performed within HyperSizer ${ }^{\mathrm{TM}}$. The major structural components were divided into skins, bulkheads, and two keel beams as previously described. The various components of the vehicle, such as the keels and bulkheads shown in Figure 11 below, were sized using different structure concepts. All metallic materials were first tried consisting of titanium and aluminum-lithium. Problems encountered with the composite X-33 LH2 cryo tanks as well as the panel sizing results previously discussed have prompted the use of metallic tanks for this study and an all-metallic airframe.

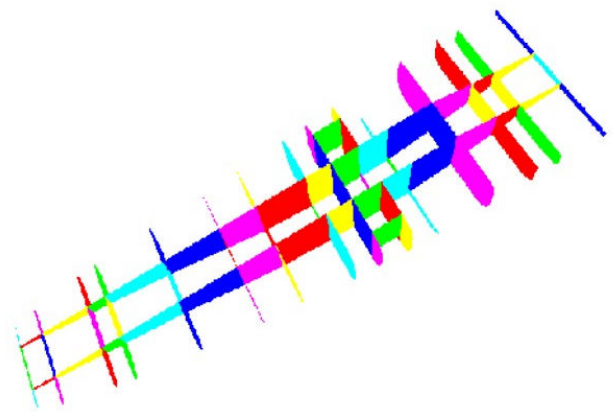

Figure 11. Keels and bulkheads

The initial material was all aluminum with 1" thick keels/bulkheads and a .1" skin. The model is symmetric along the centerline with no control surfaces or engine geometry. These were modeled as lumped masses distributed at fuselage attachment points. Internal lumped masses were estimated for the LOX and LH2 tanks, landing gear, engine and sub systems. TPS sizing and thermal effects on the structure were not considered during this study. Future enhancements to HyperSizer ${ }^{\mathrm{TM}}$ will combine TPS and panel sizing. This should greatly improve the preliminary design process for weight estimation. The aero loading case considered was for a single point along a trajectory curve that produced the worst case loading. The model was trimmed by moving the engine weight and calibrating the vertical force on the horizontal tails. A $1.5 \mathrm{~g}$ vertical acceleration was also 
applied along with a factor-of-safety of 1.5 on the ultimate stress of the materials. Mid-span deflection limits were also held to less than $1 \%$ of the span length. The extensive flight envelope inherent in air breathing hypersonic vehicle designs involves many interdependent disciplines with large sets of control variables. ${ }^{2}$ The intent of this design study was to take a quick look at possible structural concepts due to a single worse case load. A higher order analysis would require refinement of the loading definitions along many possible trajectory points and analyzing the vehicle as the cg changes with propellant use.

Supports for the LOX tanks were provided by a system of single DOF connections as shown in Figure 12. The determinate connections allow for relative thermal displacements between the LOX tank and keel beams. The panels above the LOX tank as well as the payload doors were not included in the analysis. The panels were removed to provide access and possible tank replacement/inspection. The planform of the vehicle in Figure 3 shows the areas on the top surface where panels were removed. The continuous connection of the LOX access panels and payload doors to the adjoining structure could not be assumed and will certainly add conservatism into the analysis. The removal of the panels redistributes and increases bending loads into the keel beams and creates an open section for shear flows. It may be possible to design a mechanism for a continuous load path into the LOX access panels and payload doors, however such a design is left for future analysis.

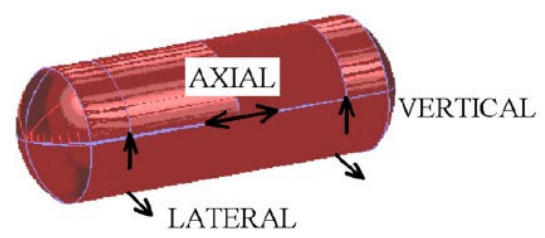

Figure 12. LOX tank support connections

Many margin checks were used during the analysis that included: panel and local buckling, crippling and strength checks. A relaxation of the panel buckling margins in the keel panel members could help reduce the section size. A separate FEA, left for future analysis, would be necessary to allow diagonal buckling of the keel panels.

Results obtained from HyperSizer ${ }^{\mathrm{TM}}$ were analyzed to find an airframe structure producing the lowest weight and reasonable section geometry. The analysis varied combinations of the following structural concepts: bladed stiffened, corrugated and isogrid panels. ${ }^{6}$ Each combination produced different weights and load paths according to the panel stiffening method chosen. Some of these results are shown below in Tables 1-3.

Table 1 shows the optimized structural sizing results for the bladed panel stiffening method. This method produced the heaviest airframe at 12.87 psf or 539,556 lbs overall. The blade thickness was allowed to vary from 0.1 to 0.5 inches and the depth from 1 to 12 inches. The skins were also given a range from 0.1 to 0.75 inches. Stiffener spacing ranged between 2 and 10 inches.
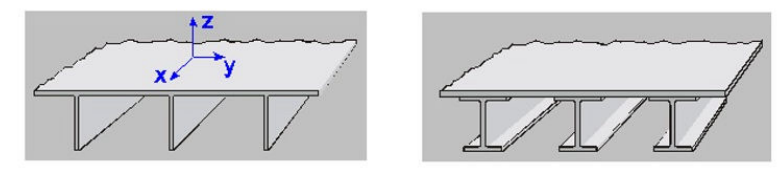

\begin{tabular}{|l|l|l|l|}
\hline $\begin{array}{l}\text { BHDS } \\
\text { (bladed) }\end{array}$ & $12.29 \mathrm{psf}$ & $116,114 \mathrm{lbs}$ & $21.51 \%$ \\
\hline $\begin{array}{l}\text { KEELS } \\
\text { (bladed) }\end{array}$ & $15.94 \mathrm{psf}$ & $103,086 \mathrm{lbs}$ & $19.10 \%$ \\
\hline $\begin{array}{l}\text { SKINS } \\
\text { (bladed) }\end{array}$ & $12.32 \mathrm{psf}$ & $320,376 \mathrm{lbs}$ & $59.39 \%$ \\
\hline Total Wt. & $12.87 \mathrm{psf}$ & $539,556 \mathrm{lbs}$ & \\
\hline
\end{tabular}

Table 1. Results for blade stiffen panels

Panels were grouped into optimization zones outlined by the keels and bulkheads. These structural zones represented the smallest practically manufacturable piece of the vehicle. ${ }^{7}$ HyperSizer ${ }^{\mathrm{TM}}$ was allowed to choose either integrally stiffened or "I" stiffened panels for the optimal design. Most panels chosen were the "I" stiffened type with aluminum skins and titanium stiffeners. HyperSizer ${ }^{\mathrm{TM}}$ could select titanium when higher strengths were required to support the larger LH2 volumes near the vehicle c.g.

Table 2 shows the results of isogrid keel panels and corrugated stiffened bulkhead and skin panels. The corrugated stiffening method lowered the weight for bulkheads and skins by half. The dimensions of the isogrids were varied until an optimal size was achieved. Blade thickness and depths were varied for a general grid with both single and double face sheet. The corrugated stiffening method, chosen for the bulkheads and skin panels, used single and sandwich face sheets. Panel thickness, stiffener spacing and depths were also varied. Table 2 shows the panel concepts and the airframe weight of 7.24 psf or a total structural weight of $303,400 \mathrm{lbs}$.

The final optimized corrugated panel designs were aluminum with skin thickness ranging from 0.1 to 0.5 inches and a core web thickness of .1 inch. A bottom sheet was selected by HyperSizer ${ }^{\mathrm{TM}}$ to achieve an 

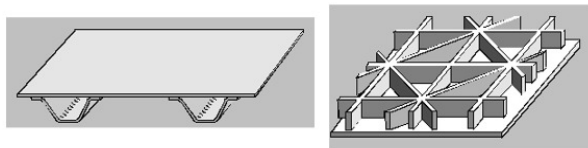

\begin{tabular}{|l|l|l|l|}
\hline $\begin{array}{l}\text { BHDS } \\
\text { (corrugated) }\end{array}$ & $5.19 \mathrm{psf}$ & $49,018 \mathrm{lbs}$ & $16.15 \%$ \\
\hline $\begin{array}{l}\text { KEELS } \\
\text { (isogrids) }\end{array}$ & $13.62 \mathrm{psf}$ & $91,770 \mathrm{lbs}$ & $30.25 \%$ \\
\hline $\begin{array}{l}\text { SKINS } \\
\text { (corrugated) }\end{array}$ & $6.26 \mathrm{psf}$ & $162,612 \mathrm{lbs}$ & $53.60 \%$ \\
\hline Total Wt. & $7.24 \mathrm{psf}$ & $303,400 \mathrm{lbs}$ & \\
\hline
\end{tabular}

Table 2. Results for corrugated and isogrid panels

optimal section. The spacing of the corrugation also varied between 4 and 8 inches and the depth ranged from 2 to 10 inches.

The isogrid structural concept, applied to the two keel beams, had web stiffeners running in three directions: fore/aft, vertical and diagonal. Structural weights were compared with the blade-stiffened concept that had only vertical stiffening. The final optimized isogrid reduced the design weight of the keels by $11,200 \mathrm{lbs}$. The added tridirectional stiffeners in the isogrid increased the bending stiffness to resist vertical inertial loads and the internal LH2 tank pressures. The isogrid keel design will also help in reducing thermal forces and moments induced from temperature gradients of the cryogenic fluids. The temperature effects are smaller for web-stiffened panels than they are for sandwich type panels.

The results for an all corrugated stiffened airframe are given in Table 3. This stiffening method produced the lowest airframe weight of $6.05 \mathrm{psf}$ or 253,512 lbs for the total structure. The corrugated stiffeners allowed the skin panels to carry greater bending loads that helped to reduce the keel weights. Just as in previous stiffening methods, dimensions and number of face sheets were allowed to vary. This method produced an all aluminum structure with minimal thickness.

Most of the skin panels were made up of .1 inch top and bottom aluminum face sheets and corrugated webs. The depth of the final panel size varied from 2 to 5 inches with the web core spacing of 4 inches. The keel panels required an increase in face sheet thickness to 0.25 inches and the depth range also increased to 8 inches.

Each stiffening method offered unique attributes for operating in a cryogenic environment. The uniaxial integral blade produced the heaviest airframe but would

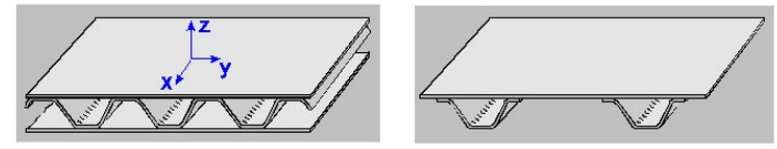

\begin{tabular}{|c|l|l|l|}
\hline $\begin{array}{c}\text { BHDS } \\
\text { (corrugated) }\end{array}$ & $5.13 \mathrm{psf}$ & $48,550 \mathrm{lbs}$ & $19.15 \%$ \\
\hline $\begin{array}{c}\text { KEELS } \\
\text { (corrugated) }\end{array}$ & $6.55 \mathrm{psf}$ & $42,348 \mathrm{lbs}$ & $16.70 \%$ \\
\hline $\begin{array}{c}\text { SKINS } \\
\text { (corrugated) }\end{array}$ & $6.26 \mathrm{psf}$ & $166,612 \mathrm{lbs}$ & $64.15 \%$ \\
\hline Total Wt. & $6.05 \mathrm{psf}$ & $253,512 \mathrm{lbs}$ & \\
\hline
\end{tabular}

Table 3. Results for corrugated panels

be the easiest to perform tank inspections. The corrugated panels are the lightest but could require lengthy inspection procedures. However, they could be used for insulation, fuel lines, piping and wiring.

\section{Conceptual Mars Aerocapture Vehicle}

An unmanned exploration vehicle capable of delivering a parachute deployable lander and an orbiting science package was designed for an aerocapture mission at Mars. The rigid slender body aeroshell has a unique cylindrical shape called an ellipsled that produces the necessary lift and drag required for aerocapture at Mars. The structure is divided into the forebody, which supports a heatsheild and a backshell that gets ejected prior to lander deployment. Figure 13 shows the aeroshell structure with its backshell removed to reveal the lander capsule and internal structure. The lander is angled inside the aeroshell to allow the largest volume enclosed by the aeroshell as well as a safe exit of the lander.

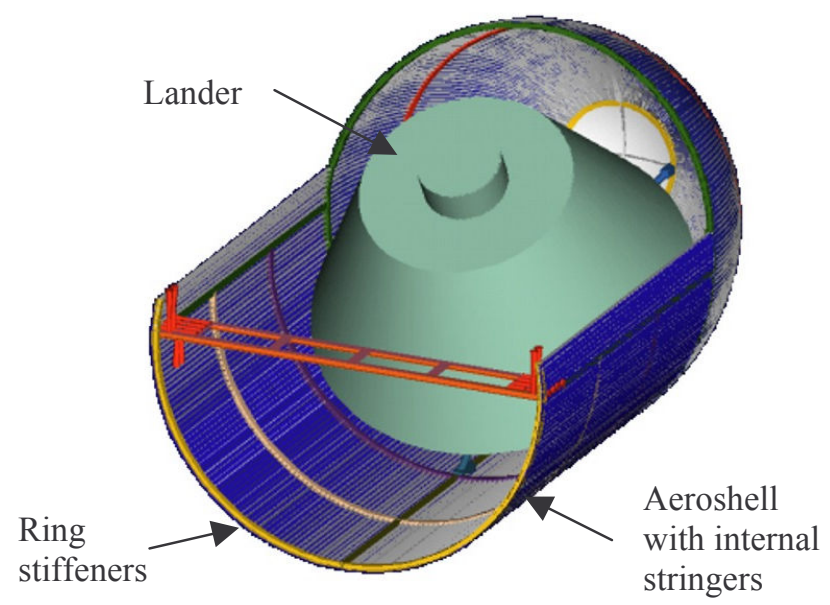

Figure 13. Ellipsled with lander-Backshell Removed

The main aeroshell structural members consist of ring and longitudinal tee stiffeners with skin panels. Stiff tubular members support the lander and are used in 
attaching the aeroshell. Johnson Space Center (JSC) had performed a detailed FEA of the aeroshell structure in launch and entry configurations to obtain weight estimates and structural member sizes. The analysis presented in this paper, using a reduced DOF FEM with a non-deterministic automating approach to size the skin panels, was done as an enhancement to JSC's efforts. The skin design must be as light as possible while resisting aerodynamic, inertia, thermal and launch loads. The goal of the analysis was to reduce the weight of the aeroshell and evaluate the overall performance of the structure using HyperSizer ${ }^{\mathrm{TM}}$.

\section{Automating approach}

Structural sizing of the aeroshell was performed with a typical finite element approach coupled with the nonFEA sizing tool HyperSizer ${ }^{\mathrm{TM}}$. The original JSC FEM was difficult to modify since longitudinal blade stiffeners were individual modeled. The FEM mesh would be altered for any change to the stiffeners thus requiring the model to be recreated and solved many times. HyperSizer did not require a revised, highly dense mesh but operated on a coarsely meshed FEM for stiffener spacing. The skin panels can be stiffened or sandwich shapes with optimal fiber angles and stacking sequencing of the lay-ups in composite panels being defined by the tool. HyperSizer computes the optimum stiffness distribution of the aeroshell while automatically achieving positive margins for strength and stability.

\section{Analysis}

The original FEM created by JSC to size the aeroshell and estimate the vehicle structural weight was reduced in size and analyzed inside HyperSizer ${ }^{\mathrm{TM}}$. The analysis involved reducing a 419,200 DOF FEM into a coarsely meshed 7000 DOF model. The larger model had individual stringers, longerons and ring stiffeners modeled with shell elements while the smaller model incorporated these into the shell elements. Figure 14 shows the original, larger FEM and the reduced DOF FEM used by the sizing tool.

The first attempt in using HyperSizer ${ }^{\mathrm{TM}}$ was to try to duplicate the original results from the larger DOF FEM by sizing the original skin design. The reduced FEM was analyzed using the same concentrated payload
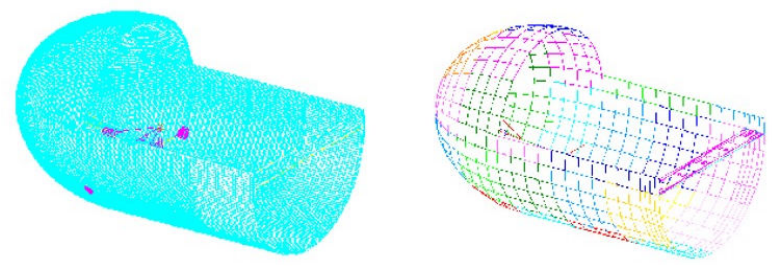

Figure 14. Ellipsled FEM's 419,200 dof vs. 7,000 dof

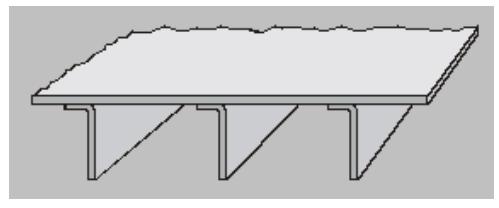

Figure 15. Blade stiffened panel

mass with rigid elements. The attachment of the rigid elements were modified to suit the modified mesh. The same Newtonian pressures used in the original model were fitted to the new mesh of the reduced model. An exact match of pressures was not possible since the mesh densities were so different. A $10 \mathrm{~g}$ acceleration was also applied to the reduced model that was the same as used in the original FEM. The same stiffener dimensions, spacing and materials were used in the coarsely meshed HyperSizer ${ }^{\mathrm{TM}}$ model to nearly match the original FEM structure.

After applying the above loads to the reduced model, a NASTRAN analysis was performed using inertia relief. The technique is the same used in the original model and uses the mass of the model to resist the applied load. The resultant loads were then read into the reduced DOF HyperSizer ${ }^{\mathrm{TM}}$ model. The skin elements were first grouped inside the tool to size the bladestiffened panels of the JSC model. The skin was modeled as graphite/BMI "IM7-5250" with 5 ply at 0,45,90,-45 and 0 degrees. The blades were Al 7075 and were modeled as angled stiffeners to allow a connection for the skin. Figure 15 shows a typical blade stiffener used in the HyperSizer ${ }^{\mathrm{TM}}$ analysis. Margins of safety were 1 on yield and 1.5 on ultimate.

After matching the detailed FEM with the reduced DOF model, another analysis was performed inside HyperSizer $^{\mathrm{TM}}$ to optimize the bladed panel concept. In this analysis the blade geometry and spacing was allowed to change but the skin and blade material remained IM7-5250 and Al 7075 respectively. Various other blade concepts available inside HyperSizer ${ }^{\mathrm{TM}}$ were also attempted and are shown in Figure 16.
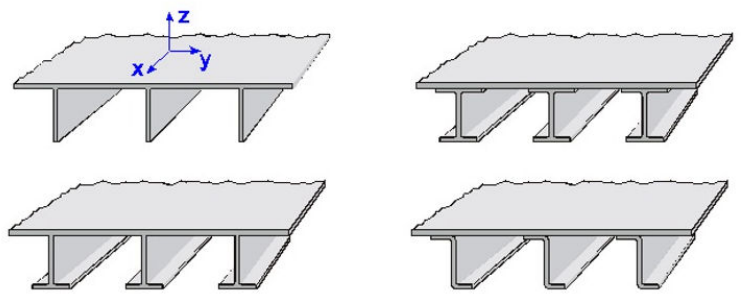

Figure 16. Blade Stiffened Concepts 


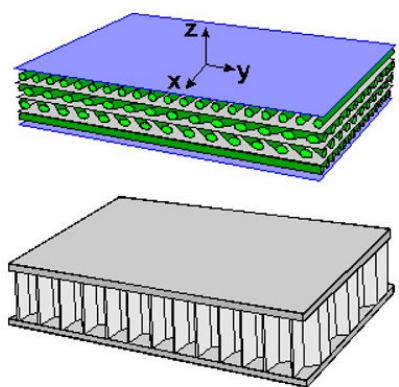

Figure 17. One Stack Unstiffened and Honeycomb Sandwich

Other materials and panel concepts were allowed in an attempt to reduce the aeroshell weight while still holding margins. Unstiffened honeycomb and one stack unstiffened panel concepts were sized using the same loading used in the bladed panel design. The facesheet materials allowed to be selected were IM75250, Al 7075 and Ti-6Al. The core materials were a variety of Hexcell HRH and Ti-3Al with different densities. These materials were made available during the HyperSizer ${ }^{\mathrm{TM}}$ optimization and were to test material combinations of the honeycomb. The minimum core thickness was held at 0.5 " with the maximum allowed at 1". Figure 17 shows the one stack unstiffened and honeycomb sandwich panels used in the optimization.

\section{Results}

The results for reducing the aeroshell skins are summarized in Table 4 below. The original skin weight was reduced from $.69 \# / \mathrm{ft}^{2}$ to $.55 \# / \mathrm{ft}^{2}$ while passing failure criteria. The results show honeycomb composite skins may help reduce the aeroshell weight.

Model 1, shown in Table 4, is the original blade stiffened design analyzed in HyperSizer ${ }^{\mathrm{TM}}$ using IM7 skin and stiffeners. The design performed well under general stress analysis and modal checks. However, the HyperSizer ${ }^{\mathrm{TM}}$ results indicated localized panel buckling and crippling in some areas of the shell. An increase in stiffener size would be necessary for the panels to pass all failure criteria and would also increase the weight. Model 2 is the same as the first model but uses Al stiffeners. This increases the unit weight to $1.0 \# / \mathrm{ft}^{2}$ and does not pass all the failure criteria. Model 3 allows HyperSizer ${ }^{\mathrm{TM}}$ to optimize model 2. This saves some weight by reducing the unit skin weight to 0.93 $\# / \mathrm{ft}^{2}$ and passes all failure criteria.

Model 4 switches the skin panel design from the previous blade stiffened to honeycomb. Model 4 skin panels were Al 7075 with Hexcell HRH cores. The HyperSizer $^{\mathrm{TM}}$ results gave a unit panel weight of 0.69 $\# / \mathrm{ft}^{2}$ while still passing the failure criteria for

\begin{tabular}{|c|c|c|c|l|}
\hline Model & $\begin{array}{c}\text { Skin } \\
\text { Wt. } \\
\#\end{array}$ & $\begin{array}{c}\text { Unit } \\
\text { Wt. } \\
\# / \mathrm{ft}^{2}\end{array}$ & $\begin{array}{c}\text { Failure } \\
\text { check }\end{array}$ & \multicolumn{1}{|c|}{$\begin{array}{c}\text { Aero Panel } \\
\text { Description }\end{array}$} \\
\hline 1 & 386 & 0.69 & Fails & $\begin{array}{l}\text { Original blade } \\
\text { stiffened panel, } \\
\text { IM7-5250 skin \& } \\
\text { stiffeners }\end{array}$ \\
\hline 2 & 567 & 1.0 & Fails & $\begin{array}{l}\text { Original blade } \\
\text { stiffened panel, } \\
\text { IM7-5250 skin \& Al } \\
7075 \text { stiffeners }\end{array}$ \\
\hline 3 & 529 & 0.93 & OK & $\begin{array}{l}\text { Optimized blade } \\
\text { stiffened panel, } \\
\text { IM7-5250 skin \& Al } \\
7075 \text { stiffeners }\end{array}$ \\
\hline 4 & 389 & 0.69 & OK & $\begin{array}{l}\text { Honeycomb w/ Al } \\
7075 \text { skin \& Hexcell } \\
\text { HRH core }\end{array}$ \\
\hline 5 & 312 & 0.55 & OK & $\begin{array}{l}\text { IM7-5250 skin } \\
\text { Hexcell HRH core }\end{array}$ \\
\hline
\end{tabular}

Table 4. Weight Summary

honeycomb panels. Model 5 produced the lowest weight panel of $.55 \# / \mathrm{ft}^{2}$. The skin was a 5 ply Graphite/Epoxy "IM7-5250" with a Hexcell HRH core. The core thickness was allowed to vary from 0.5 " to 1 " however HyperSizer ${ }^{\mathrm{TM}}$ gave a 0.5 " core for all panels.

A NASTRAN modal analysis was performed using the optimized honeycomb panels from HyperSizer ${ }^{\mathrm{TM}}$. The results indicated a $1^{\text {st }}$ torsion mode at $8.16 \mathrm{~Hz}$ as shown in Figure 18. The cut in the cylindrical cross section of the Ellipsled severely lowered its ringframe stiffness. It is not known if there is a minimum structural frequency requirement during planetary entry. A $10 \mathrm{~Hz}$ lateral and $27 \mathrm{~Hz}$ axial frequency limit is suggested during launch in the Boeing Co. "Delta IV Payload Planners Guide" If a higher frequency is required for entry then it will be necessary to stiffen the aeroshell to resist twisting. Unfortunately the frequency requirement will drive the design and a large structural weight increase will occur.

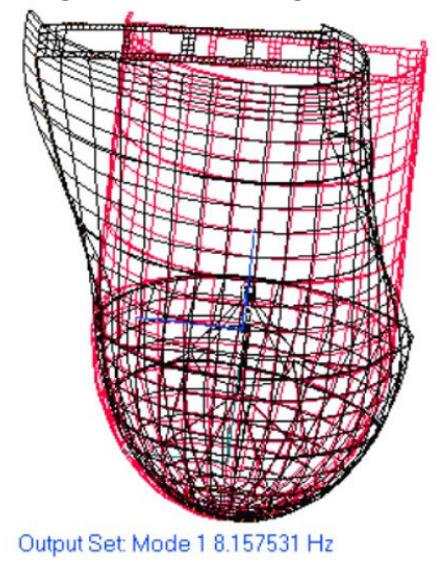

Figure 18. Torsion mode 


\section{RLV Sizing}

\section{$\underline{\text { Conclusion }}$}

The $3^{\text {rd }}$ generation concept vehicle was analyzed using the HyperSizer ${ }^{\mathrm{TM}}$ structural sizing software.

Preliminary sizing results for LH2 and LOX tanks showed conformal tanks could be designed for LH2 but not for LOX. The conformal LOX tank configuration had large panel displacements from the LOX inertia loads. The structure necessary for the panel displacements to be contained within margin created an unrealistic design. The displacements could be reduced with multiple tension membranes, however this also produced a heavy vehicle. Single lobed non-conformal LOX tanks were used but not sized in this study. Their weight contribution and tank reactions where included in the design. The analysis focused on sizing conformal tanks for LH2 and arriving at a preliminary structural weight estimate of the vehicle. Results for a $1.5 \mathrm{~g}$ vertical acceleration with a 1.5 factor-of-safety gave an optimized all aluminum structure built with corrugated panels. The final structural weight of the optimal design would be $253,512 \mathrm{lbs}$. for an overall fully fueled vehicle weight of 1,374,436 lbs. This included all weight estimates for the engine, fuel, LOX tank structure, control surfaces, payload and landing gear.

Analyzing the $3^{\text {rd }}$ generation concept vehicle and optimizing the vehicle's design demonstrated the use of HyperSizer $^{\mathrm{TM}}$ in a conceptual design. The software saved analysis time by performing margin of safety checks on the $3^{\text {rd }}$ generation design without any modeling changes to the FEM. Another time saver was that during the analysis only a coarse meshed FEM was required. No detailed modeling of the stiffened panels was needed, just regular shell element properties. Engineering time was further saved by not running a FEA buckling analysis and detailed panel sizing was quickly performed without a re-meshing of the finite elements. ${ }^{4}$ The benefits of HyperSizer ${ }^{\mathrm{TM}}$ were also shown in performing parametric studies on the conceptual vehicle design. The optimization process inside HyperSizer ${ }^{\mathrm{TM}}$ efficiently reduced the structural weight of the vehicle through selecting the best structural concept and giving optimal dimensions and material while performing strength and buckling margin checks.

No thermal effects were included during the structural sizing of the vehicle described in this paper. The next level of analysis would add temperature gradients from the aero-thermal loads on the outer skin panels and cryogenic temperatures along the interior panels of the conformal LH2 tanks. Determinate load paths from the LOX tanks were used to help isolate the tank and manage the DOF of the thermal displacements. Single DOF tank supports could be designed to allow thermal expansion/contraction and reduce stress concentrations at tank connections to the keels and bulkheads. Further use of isogrids will also help during a thermal analysis to reduce internal stresses and moments. No TPS sizing was performed however future upgrades of HyperSizer $^{\mathrm{TM}}$ will allow TPS sizing and enhance the structural weight estimate.

HyperSizer $^{\mathrm{TM}}$ is included in NASA's design methods for the $3^{\text {rd }}$ generation RLV. The software's fast optimization ability will continue to be used as later generation vehicle concepts are reviewed and improved. The agency's ISAT team has recognized HyperSizer $^{\mathrm{TM}}$ as a modern structural sizing tool that can quickly improve weight and stiffness requirements for future vehicles.

\section{Aerocapture Aeroshell Sizing}

A slender body aerocapture aeroshell was also sized using HyperSizer ${ }^{\mathrm{TM}}$. The aeroshell structure was initially analyzed with a detailed FEM using NASTRAN to size a system of ring and internal longitudinal stiffeners. The aeroshell was later reanalyzed with HyperSizer ${ }^{\mathrm{TM}}$ to investigate other possible structural concepts that could possibly reduce

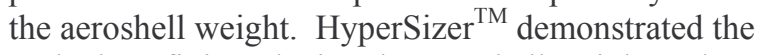
tool's benefit in reducing the aeroshell weight and shorten the time of designing conceptual aerocapture spacecraft. The tool can provide mission planners with reliable structural weight estimates without requiring a detailed FEA. Once the tool sizes the structure, a refined FEM of the structure can be created for finalizing the design. Time spent defining revised finite element meshes is minimized since HyperSizer ${ }^{\mathrm{TM}}$ reuses the same mesh geometry and automatically chooses minimal structural concepts

\section{Acknowledgements}

The author wishes to recognize the following for their contribution to the design and analysis of the Mars aerocapture aeorshell: Maria Fiorenza and Jonathan Bowie from Johnson Space Center, Craig Collier and Phil Yarrington for instruction and help in HyperSizer $^{\text {TM }}$.

\section{References}

1. J. T. Dorsey, D. E. Myers, C. J. Martin, "Reusable Launch Vehicle Tank/Intertank Sizing Trade Study", AIAA-2000-1043.

2. G. A. Hrinda, "Integrated Structural Analysis of the X-43 Using HyperSizer ${ }^{\text {TM }}$ Sizing Software", CS/PSHS/APS Joint Meeting, November 2000.

3. R. W. Powell, M. K. Lockwood and S. A. Cook, "The Road from the NASA Access-to-Space Study to a Reusable Launch Vehicle", IAF-98-V.4.02, $49^{\text {th }}$ International Astronautical Congress, Sep. 28-Oct. 2, 1998/Melbourne, Australia. 
4. Collier Research Corporation, "HyperSizer ${ }^{\mathrm{TM}}$

Tutorial \& Applications", $2^{\text {nd }}$ edition, Collier Research Corporation, 1998.

5. C. S. Collier, P. W. Yarrington and M. Pickenheim, "Design Optimization Using HyperSizer ${ }^{\mathrm{TM}}$,, Collier

Research Corporation, The 1998 MSC Americas Users Conference, Universal City, CA, Oct 5-8, 1998.

6. C. S. Collier, P. W. Yarrington and M. Pickenheim, "Analysis and Optimization of the Grid-Stiffened

Family of Panel Concepts", Collier Research

Corporation, January 2000.

7. C. S. Collier, P. W. Yarrington and M. Pickenheim, "Next Generation Optimization Today", The 1997

MSC Aerospace Users Conference, Newport Beach, CA, November 18-20, 1997.

8. "Delta IV Payload Planners Guide", The Boeing Company, Huntington Beach, CA, 2000. 